\title{
Computer Simulation Instruction: Carrying out Chemical Experiments
}

\author{
Ibtesam Al-Mashaqbeh \\ Department. of Computer Science, Al al-Bayt University?(AABU), Mafraq-Jordan \\ Email: ibtesamirbid@yahoo.com
}

\begin{abstract}
The purpose of this study was to investigate the effect of computer simulation Instruction (CSI) on students' achievements: Carrying out chemical experiments to acquire chemical concepts for eleventh grade students. The subject of the study consisted two sections of a one girl's high school in Jordan. One section was randomly assigned to experimental group in which computer simulation Instruction (CSI) was used, and the other section was randomly assigned to control group in which students were instructed by using the traditional teaching instruction.

The findings indicated that there is progress on the part of the experimental group which used the computer simulation Instruction (CSI) and this was reflected positively in the students' achievement in carrying out chemical experiments to acquire chemical concepts.
\end{abstract}

Index Terms-Simulation method, computer-assist learning, teaching chemistry, computer-assisted instruction Material.

\section{INTRODUCTION}

Using computer simulation instruction to curry out chemical experiments was the focus of this study. The researcher believed that computer applications help students to use the technology to support their learning. The world's progress is measured by its progress in the field of science and technology, which is moving towards the atomic and technological age that focuses on discovering the secrets of the universe and the exploitation of all energies to the service of humanity [1].

Current century live the science development in the field of computer use, accompanied by the development of methods of learning and teaching. No longer had schools function confined to the provision of information by the teacher, but they depend on technology of the Internet and educational software methods that support the education process. The information revolution and technology in this era came in various ways and accelerated to the service of humanity and increasing knowledge and raise expertise in the field of specialization [2]. The industrial age of passive learning has transformed into the information age of active learning, requiring a shift from a teaching based model of education to a learning based modality [3]. The development of technology and multimedia contribute to produce computerized educational programs that make the learning process more fun and easy, through the presentation of educational material and scientific concepts in interesting ways, including image, audio, and text and interaction [4].

\section{A. Simulation method}

Simulation is a teaching strategy that replicates reality phenomenon or process by integrating cognitive, affective, and psychomotor learning domains that allows or requires learners to apply theory to practice [5]. Using Simulations method in teaching could challenge students to analyze and understand information which lead them to make critical decisions. It is providing a variety of pedagogy learning process that gives students a rapid feedback for their learning performance. A simulation method allows students to have a direct learning experiment with new ideas and phenomena. A successful simulation process offers many opportunities for rich discussion and powerful learning events in the classrooms [6]. Simulations have been used as early as year 1910 as a training strategy to reduce errors and improve safety [7]. Military have used simulation-based training strategy to offers a realistic, safe, cost-effective, and flexible learning environment to support training process [8].

Computer simulations take a number of forms: they may contain elements of a game, a role-play, or an activity that acts as a metaphor. This method has many advantages that make learning process more enjoyable and motivate learners by using many learning activities. It also enhances the critical thinking process [9]. It is an excellent way for students to create a learning experience and opportunities to practice problem solving skills in a safe and controlled environment [10]. Using style of computer simulation can achieve few objectives: development of the student's ability to make decisions and solve problems, increase the motivation and excitement for learning, and increase the effectiveness of learning. That could be achieved through repetition that train students to do some exercises, and promote students to do required responses related to educational objectives. Simulation method use educational technology to create a virtual learning environment displays three-dimensional phenomena closer thoroughly to the real situation on the ground [11].

Variety of computer applications and the use of multimedia have led to increased production of computerized educational software. Also, it led to the use of simulation software to better accommodate students' understanding of scientific concepts. Simulation software 
converts a large number of practical attitudes to computer algorithms. which make it possible to work on the educational software that design by using simulation software and multimedia technologies that match the real positions by using mathematical models. Through these educational software learner can conduct difficult scientific experiments to carry out in the school laboratory. It makes learners feel thrilled and motivated for learning, which becomes more realistic, and useful [12]. Simulation software should provide students with realistic manner by using multimedia applications. This Advanced technical style used to learn scientific concepts through computerized educational program that support active learning. This method is an incentive for learners and it able to make them learn understands science concepts. It is an event to resemble chemical experiments as closely as possible to lab experiments [13].

Simulation is an excellent teaching strategy for different science skills. It helps students receive an immediate feedback on their learning levels. It is a teaching method that required students to think though learning new information and predict outcomes are more effective than traditional teaching that depends on using lecturing method to provide students with information and outcomes [14]. Teaching science is a learning process that involves students on lab experiments and hands on activities, but there are situations when it is impossible for students to participate in certain science experiments. For many reasons: cost, time, safety issues, or accessibility that make students are unable to engage in certain activities. Computer simulations can be an effective approach to solve this problem [15].

The emphasis in teaching by simulation is on the integration process of the new knowledge, skills, and critical thinking. Unlike the traditional classroom setting simulation process allows learners to function in the learning environment that is as close as possible to an actual situation, which provides them an opportunity to make right designs. Teaching strategies used Computer simulation process to teach theory, assessment, technology, and skills [16]. Simulation has been successfully used to teach in different learning strategy in both laboratory and formal setting [17].

In the mid-sixties simulation method was considered as a way of active teaching process, especially with the experiments. The computer simulation method help reduce costs of material and moral damage resulting from applying laboratories experiments, which requires physical potential and preparation process [18]. Students used computer simulations method report that they feel more confident in their skills when later working with real materials [19].

There are several types of simulation as follows:

1. The first type of simulation material or physical Simulation: This type addresses physical material to be used, such as: the flight simulators and the use of chemicals experiments tools.

2. The second type is procedural simulation that aims to learn a series of actions or procedures, such as: training students how to run machine or device, and use it to diagnose certain diseases in the field of medicine.

The third type is the Situational Simulation, where the learner has a key role in the learning process to understand the scientific ideas not just learn the rules and strategies, the role of the learners in this type is to discover appropriate responses to situations through repeated simulations.

The last type is Process Simulation; in this type the learner does not have any role in the program process [20].

Simulation method has been used for training on various life events for example, a game of chess that is designed to simulate military operations. Most of the Greek philosophers focused on the importance of training strategy on the attitudes of learning life skills. Simulation method contributes to enabling learners acquired the suitable skills. It helps transfer what the student has learned in position that applied to similar situations in real life. The transfer and application of information gained in new situations help to increase the efficiency of the learner. The use of simulation method to assistant learning help reduces the time to learn new concepts or phenomena compared to the time needed in the real lab experiments [21].

Simulations can enable students to develop familiarity with an activity before they engage in it, as an example of simulation educational programs: Chemsense simulation program that provides an opportunity for students to explore chemical processes. This program helps students to correct errors and misconceptions in their thinking by allowing them to test out hypotheses. Froguts simulation program, is another example of simulation programs, it enable students can use an interactive computer program to proceed fully through a frog dissection before attempting dissection of an actual frog. Rabbits and Wolves simulation program, is simulation learning programs which enable students explore strategies to keeps balance on nature by varying the number of rabbits and wolves that live in a defined space. It includes directions and activities for students as well as background information for teachers. BBC Science simulation program, It provide students with the opportunity to explore virtual science experiments on a variety of topics including, plant growth, electricity, forces, friction, and food chains. Virtual Labs simulation program, it enables students to conduct experiments on a variety of topics. It can easily run thousands of experiments, changing the variables and getting results in minutes [22].

\section{B. Teaching Science with Computer Applications}

A study was conducted entitled "The effect of using computerized educational program in teaching chemical concepts and conducting lab experiments in the ninth grade students achievements: chemistry and earth sciences". The purpose of this study was to explore the 
effect of using computer in chemical experiments on the ninth graders achievement in chemistry and geology subject. The findings of the study shows that there were statistically significant differences in the achievement of ninth graders in chemical and geology subject attributed to the method (using computer in chemical experiments) [23].

A study entitled "The effect of using computers and the Internet in the achievements of eighth graders students in the Study of Science compared to the traditional way of teaching in Al-Mafraq city, University of Sharjah" was contucted to investigate the impact of computers and the Internet on the achievements of eighth grade students. The finding of the study reveals that there were statistically significant differences at the level (0.05) due to the method of teaching, which indicates that, the difference between teaching methods in favor of the experimental groups [24]. Studying the impact of lab experiments on students learning a study entitled "The impact of the use of virtual laboratories in learning laboratory experiments skills for third grade students in secondary schools in Jeddah" was conducted. The researcher used the quasi-experimental design. The study instruments were prepared by the researcher: first note card of practical experience, and second was a questionnaire to measure the students' achievements. The results of the study concluded that there are significant differences between the mean scores in the topic of anatomy skills, science skills, and physiology of the organism for students of the experimental group and control group in favor of the experimental group [25].

A study entitled "Effectiveness of a multimedia program for the development of concepts and health awareness in sciences for sixth grade students"study aimed to find out the effectiveness of the multimedia program on the development concepts of health and health awareness among sixth grade students in the City of Gaza. Researcher has used the structural method by design a multimedia program. The program was used to determine the impact on students learning. The finding of the study indicated that there were statistically significant differences in the average of students' achievement in favor of the experimental group due to teaching method [26]. A study entitled "The impact of the use of multimedia on the achievements of second-graders students in science in Riyad city" was conducted to identify the differences in the second grade students' average in science depend on the teaching method. The finding of the study indicated that there were statistically significant differences in the average of students' achievement in favor of the experimental group that studied using multimedia in the light of Bloom's Taxonomy (remember, understand, and apply) [27]. The study entitled "The effectiveness of simulation programs in achieving laboratory skills among high school students" to examin the use of program based on simulation process. The sample of the study were three groups: first group is considering using a program based on simulation-style individual learning, and the second group using a program based on simulation-style learning in small groups and the third group studying regular lab teaching. The finding of the study indicated that using program based on simulation process more effective than laboratory method. It helps students to acquire the laboratory skills by remembering and understanding, and applying new knowledge [28]. A study was held entitled "The impact of the use of computers in teaching physics in the achievements of female students and their motivation to learn". This study aimed to investigate the effect of the use of computers in teaching physics in the students' achievement and their motivation towards it. The researcher designs a computerized educational program to provide educational material. The result of the study indicated that the use of computers program has a clear impact in increasing the achievements of experimental group and motivate them to learn physics analogy compared to control group students [29].

A Study investigated the effect of teaching through computer and use the experimental method to solve problems on the education outcomes in the field of science education. The results of the study showed that students who studied using the method of problem solving and computer applications have a higher score in their achievement test [30]. Studying the effect of simulation programs on seventh grade students learning achievements'. It found that using simulated frog dissection instead of an actual dissection resulted in significantly better understanding of the anatomy than dissection method alone [31].

This paper is organised to explain the important and the purpose of the study, followed by the methodology, the results and discussion, and the conclusions.

\section{THE STUDY}

\section{A. The important of the study}

Simulations method is considered as educational software that support the learning process in many subject [32]. Learning and understanding of scientific concepts helps keep the impact to learn and helps students gain more field experience and build on it. Traditional teaching methods for these concepts rely on theoretical frameworks and descriptive method. It sometimes applied experiments in the laboratory if the appropriate conditions are created for it. Multimedia can gives the opportunity for the learner to interact with the scientific material presented, which help teachers build learning environments using the simulation strategy software's to held the chemical experiments to illustrate various scientific concepts.

Due to the development of computer technology software, the use of traditional method to teach chemistry concepts and theory consider not an effective way to improve students learning. As well as due to teacher's unability to carry out chemical experiments to demonstrate lab experiments for many reasons such as: lack of time, not having the required tools, and inappropriate conditions for conducting the lab experiments. These reasons showed the need for new teaching method that 
support the chemistry learning process such as using computer software to design chemistry experiments through virtual laboratories using simulation method. That could contribute to raising the level of students' understanding new chemical concepts. Good educational software designed with using simulation method is a more effective tool to improve students' achievement.

\section{B. Purpose of the study}

The purpose of this study was to examine the effectiveness of using computer simulation Instruction (CSI) on students' achievements to carrying out chemical experiments to acquire chemical concepts for eleventh grade students compare to traditional teaching instruction (TTI). Specifically this study tried to answer the following questions:

1. Is there a significant difference on the achievement of eleventh grade students between the experimental group, who used a computer simulation Instruction (CSI) programs compared to the traditional group who used the traditional teaching Instruction (TTI) to teach new chemical concepts and conduct a lab experiments?

2. Is there a significant difference on the achievement of eleventh grade students who used a computer simulation?

\section{METHODOLOGY}

\section{A. Sample}

The present study was conducted at one secondary, girl's high school in Jordan in fall semester in 2012. It examined the two teaching methods CSI and TTI. The sample of the study consisted of eleventh grade students at one high school for girls in Jordan. A random assignment of participants to control and experimental groups was not feasible. Participants of this study were 34 students; they were divided into two groups of 17 for each group: the control group which used the TTI approach and the experimental group which used the CSI approach. The research process used the pre-test/post-test control group design.

\section{B. Research Instruments:}

\section{1- Computer simulation program}

The design of the software that based on simulation should focus on the introduction; by reviewing the contents of the simulation program in general, set the goals of the program and give students the necessary instructions to use the program. After that the learners should use smoothly the program and review their understanding of the content. The design process should focus on helping students use the educational materials and answered questions posed by the program with the availability of immediate feedback for correct or incorrect answers to record student performance [20].

To achieve the aims of the study, the computer simulation Instruction (CSI) program was used. The process of designing this program was taken several components into consideration:

- The program was appropriate to meet eleventh grade students' learning needs.

- The content of the program supported the subject objectives.

- The program was designed as user friendly it has buttons, effects, and options similar to other multimedia programs

- The instructional presentation of the program focused on using suitable multimedia that support teaching and conducting chemical experiments and used programs that support simulation methods.

- A program manual was made available to assist students in doing the chemical experiments.

\section{2- Achievement Test}

The researchers design an achievement test elements to measure students' achievement on learning chemical concepts that required chemical experiments in the topic of the three States of Materials (Solid, Liquid and Gaseous) for eleventh grade students taking into consideration the learning topic objectives. To ensure the validity and the reliability of the achievement test, a panel of five experts in teaching chemistry for eleventh grade students reviewed the test items and offered suggestions to enhance the test validity. To assess the reliability of the test, a pilot study was implemented. One week later, the same test was re-administered to the same subjects. The results were correlated using Pearson's formula and the score was 0.84 which indicated a good reliability.

\section{Procedure}

The pre-test was given to the two groups to ensure that the control group was similar to the experimental group in their previous knowledge in the required topic. The control group was taught by the traditional way of teaching chemistry. The instructor used class lecture method and lab experiments if it possible to teach the students the required materials. On the other hand; the experimental group was introduce to the designed computer simulation Instruction (CSI) program that teach new chemical concepts and lab experiments on the required topic. The computer simulation Instruction (CSI) programs included different multimedia tools to support student learning: pictures, video clips, animation and sounds were used to support simulation strategy. Everyone in the experimental group received a copy of the program by email. With the help of the chemistry teacher, the experimental group were required to us the program at home and at the computer lab in school during the chemistry class period. The post-test was given to the two groups to major students achievements. Student test 
was graded by their teachers after that the collected data were analyzed to test the different of the two group's achievements.

\section{RESULTS AND DISCUSSION}

The most prevalent findings of this study are:

Using T-Test for control and experimental group pretest to ensure the equivalent of the two group found that both group were equivalent as shown in table 1

Table 1. Paired T-Test and CI: Control-Pre-Test, Experimental-Pre-Test

\begin{tabular}{|c|c|c|c|c|c|c|}
\hline & $\mathbf{N}$ & Mean & StDev & $\begin{array}{c}\text { SE } \\
\text { Mean }\end{array}$ & $\begin{array}{c}\text { T- } \\
\text { Valu } \\
\text { e }\end{array}$ & $\begin{array}{c}\text { P- } \\
\text { Valu } \\
\text { e }\end{array}$ \\
\hline $\begin{array}{l}\text { Traditio } \\
\text { nal-pre }\end{array}$ & 17 & $\begin{array}{c}50.647 \\
1\end{array}$ & 14.7646 & 3.5809 & \multirow{2}{*}{0.45} & \multirow{2}{*}{0.662} \\
\hline Exp-pre & 17 & $\begin{array}{c}49.235 \\
3\end{array}$ & 12.7942 & 3.1030 & & \\
\hline $\begin{array}{l}\text { Differen } \\
\text { ce }\end{array}$ & 17 & $\begin{array}{c}1.4117 \\
6\end{array}$ & $\begin{array}{c}13.0482 \\
7\end{array}$ & $\begin{array}{c}3.1646 \\
7\end{array}$ & & \\
\hline
\end{tabular}

The finding that answered the first research question "is there a significant difference on the achievement of eleventh grade students between the experimental group, who used a computer simulation Instruction (CSI) programs compared to the traditional group who used the traditional teaching Instruction (TTI) to teach new chemical concepts and conduct a lab experiments?"

Means and standard deviations for post-test scores for the experimental and control groups in the achievement test are reported in Table 2. When examining descriptive data concerning the post-test for experimental group (after the application of the simulation Instruction (CSI)) and post-test for control group in the achievement scores (table 2), it was noticed that there is an increase in the mean of scores by (19) This value represents the different in students' achievement. Also, it is well-known that the standard deviation is a measure of how well the mean represents the data. Small standard deviation (relative to the value of the mean) indicates that the data points are close to the mean. A large standard deviation (relative to the value of the mean) indicates that the data points are distant from the mean, or that the mean is not an accurate representation of the data. As seen in the table 2), the standard deviation in the experimental group post-test (9.1960) is reduced compared to the standard deviation in the control group post-test (51.936), which means less data variations and pointed out that the student's scores are around the mean (83.2353).
Table 2. Descriptive Statistics for Achievements Test: Means and Standard Deviations (SD) for control post-test and experimental Posttest Scores

\begin{tabular}{|c|c|c|c|c|}
\hline & $\mathbf{N}$ & Mean & St Dev & SE Mean \\
\hline Traditional-post & 17 & 64.2353 & 51.936 & 3.8640 \\
\hline Exp-post & 17 & 83.2353 & 9.1960 & 2.2304 \\
\hline Difference & 17 & 19.0000 & 16.6433 & 4.0366 \\
\hline
\end{tabular}

To check the validity of the first hypothesis that stated (The first hypothesis: There are no differences between the achievement of eleventh grade students who have studied chemical concepts and conduct lab experiments using computer simulation Instruction (CSI) and who have studied using the traditional teaching Instruction (TTI)), the paired samples (dependent) t-test was run on the SPSS-15 program to determine any significant differences between post- and pre- test scores. The results are shown in table (3). It is clear that in table 2 and 3, the mean of the scores is increased from (49.2) to (83.24) by a difference of (34.22). The computed t-value equals (8.90) at degree of freedom equals (32) with statistical significance less than (0.000). This is less than the claimed level of significance $\alpha(0.05)$, therefore, there is significant differences at level of $\alpha(0.05)$ between the mean scores of the achievement of pre-test and post-test, favoring the post-test).

Table 3. Achievement Dependent Samples t- test

\begin{tabular}{|c|c|c|c|c|c|c|}
\hline Achievement & N & Mean & $\begin{array}{c}\text { St } \\
\text { Dev }\end{array}$ & $\begin{array}{c}\text { SE } \\
\text { Mean }\end{array}$ & $\begin{array}{c}\text { T- } \\
\text { Value }\end{array}$ & $\begin{array}{c}\text { P- } \\
\text { Value }\end{array}$ \\
\hline $\begin{array}{c}\text { Traditional- } \\
\text { post }\end{array}$ & 17 & 64.2353 & 51.936 & 3.8640 & & \\
\cline { 1 - 4 } Exp-post & 17 & 83.2353 & 9.1960 & 2.2304 & \multirow{2}{*}{-4.71} & 0.000 \\
\hline
\end{tabular}

The finding that answered the second research question (is there a significant difference on the achievement of eleventh grade students who used a computer simulation Instruction (CSI) method?) Used T-Test: for Experimental group post-test e test (two independent samples:

Means and standard deviations for pre-test and posttest scores for the experimental and control groups in the achievement test are reported in Table 4 . When examining descriptive data concerning the pre-test and post-test achievement scores (table 4), it was noticed that there is an increase in the mean of scores by (34.22) after the application of the simulation Instruction (CSI). This value represents the gain in students' achievement. Also, it is well-known that the standard deviation is a measure 
of how well the mean represents the data. As show in the table 4, the standard deviation in the post-test (9.20) is reduced compared to the standard deviation in the pretest (12.8), which means less data variations and pointed out that the student's scores are around the mean (83.24).

The paired samples (dependent) t-test was run on the SPSS-15 program to determine any significant differences between post- and pre- test scores. To check the validity of the second hypothesis that stated (There are no significant differences at $\alpha$ level of ( 0.05$)$ between the mean scores of the achievement of pre-test and posttest in the achievements of the experimental group). It is clear from table (4), table (5) and Fig. 1, that the mean in the scores is increased from (49.2) to (83.24) by a difference of (34.22). The computed t-value (8.90) at degree of freedom equals (32) with statistical significance less than (0.000). This is less than the claimed level of significance $\alpha(0.05)$, therefore, there is a significant difference at level of $\alpha(0.05)$ between the mean scores of the pre-test and post-test, favoring the post-test scores (on the achievement of eleventh grade students who used a computer simulation Instruction (CSI) method).

\begin{tabular}{|c|c|c|c|c|}
\hline & $\mathbf{N}$ & Mean & St Dev & SE Mean \\
\hline Exp-post & 17 & 83.24 & 9.20 & 2.2 \\
\hline Exp-pre & 17 & 49.2 & 12.8 & 3.1 \\
\hline
\end{tabular}

Table 4. Descriptive Statistics for Achievements Test: Means and Standard Deviations (SD) for Pre-test and Post-test Score

Table 5. Achievement Dependent Samples t- test

\begin{tabular}{|c|c|c|c|c|c|c|c|}
\hline Achievement & N & Mean & $\begin{array}{c}\text { St } \\
\text { Dev }\end{array}$ & $\begin{array}{c}\text { SE } \\
\text { Mean }\end{array}$ & $\begin{array}{c}\text { T- } \\
\text { Value }\end{array}$ & DF & $\begin{array}{c}\text { P- } \\
\text { Value }\end{array}$ \\
\hline exp-post & 17 & 83.24 & 9.20 & 2.2 & & & \\
\hline exp-pre & 17 & 49.2 & 12.8 & 3.1 & 8.90 & 32 & 0.000 \\
\hline
\end{tabular}

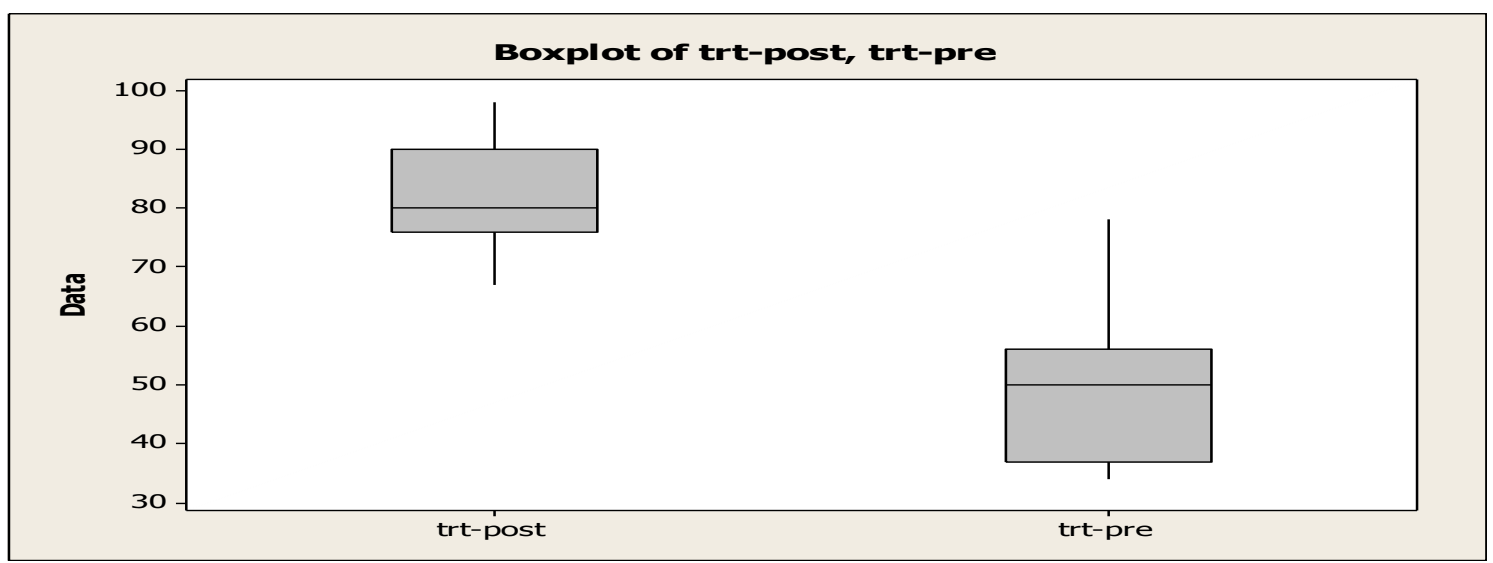

Fig 1. Achievement Dependent Samples t- test (exp-post, exp-pre)

\section{CONCLUSIONS}

The main aim of this study was to examine the effectiveness of using computer simulation Instruction (CSI) on students' achievements (experimental group) to carrying out chemical experiments to acquire chemical concepts for eleventh grade students compare to traditional teaching instruction (TTI) on students' achievements (control group). The study showed progress on the part of the experimental group which used the computer simulation Instruction (CSI) and this was reflected positively in the students' achievement in carrying out chemical experiments to acquire chemical concepts.

The significant difference in the performance of the experimental group of students could be attributed to the use of the simulation method and multimedia to design the research instrument which motivated students and gave them a chance for drill and practice and carry out the required chemical experiments. This finding is consistent with that of many other studies focused on the use of computer simulation to teach science. For example: [3], [25], [28], and [31], they found that computer simulation instruction helps students to acquire the laboratory skills by remembering and understanding, and applying new knowledge.

\section{REFERENCES}

[1] F. Deep, Preparing Teacher in the Educational Colleges. The Educational Journal, 22, 90-102, 1997.

[2] M. M. Hellah, Educational Technology Between Theory and Practice, $2^{\text {ed }}$ ed., Dar Al-Maserah for publication and distribution, Amman, Jordan, 2000.

[3] R. L. Shrigley, T. R. Koballa and R. D. Simpson, Defining attitude for science educators. Journal of Research in Science Teaching, 25, 659-678, 1988. 
[4] M, D. Majali, et al, The Multimedia, 1st ed., Aalam Alkutub Alhadethah, Jordan, Irbid, 2009.

[5] J. G. Ross, Simulation and Psychomotor Skill Acquisition: A Review of the Literature, Clinical Simulation in Nursing, 8(9), 429-435. 2012.

[6] D. Robert, Teaching with Simulations. Harvard Business School Publishing, Univ. of New Brunswick, Canada, 2011.

[7] J. E. Fowlkes, D. J. Dwyer and R. L. Oser, Event-based approach to training (EBAT). Int J Aviat Psychol, 8(3), 209-221, 1998.

[8] E. Salas, C.A. Bowers and L. Rhodenizer, It is not how much you have but how you use it: toward a rational use of simulation to support aviation training. Int. J. Aviat. Psychol, 8(3), 197-208, 1998.

[9] Saskatoon Public Schools, "Instructional strategies", http://olc.spsd.sk.ca/de/pd/instr/strats/simul/simlist.htm, 2012.

[10] K. Hawkins, M. Todd and J. Manz, A unique simulation teaching method. J Nurs Educ, 47(11), 524-527, 2008.

[11] D. Stetieh and O. Sarhan, IT: Education and E-learning, 1st ed, Dar Wael for publication, Amman, Jordan, 2007.

[12] Z. Ababneh and S. Alobeina, Educational Games in the Past and in the Computer age, $1^{\text {st }}$ ed., The Ministry of Education, Jordan, 2005.

[13] N. Abdul Hadi, Psychology of play and its Impact on Children's Learning, 1st ed., Dar Wael for publication, Amman, Jordan, 2004.

[14] P. J. Morgan, D. Cleave-Hogg, J. McIlroy and J. H. Devitt., A comparison of experiential and visual learning of undergraduate medical students. Anesthesiolog, 2-25, 96, 2002.

[15] J. Huppert, S. M. Lomask and R. Lazarowitz, Computer simulations in the high school: students' cognitive stages, science process skills and academic achievement in microbiology. International Journal of Science Education, 24(8), 803-821, 2002.

[16] C. Rauen, Using simulation to teach critical thinking skills: you can't just throw the book at them. Crit Care Nurs Clin North Am, 13, 93-103, 2001.

[17] R. H. Eaves and A. J. Flagg, The US Air force pilot simulated medical unit: a teaching strategy with multiple Applications. J Nurs Educ, 40, 110-115, 2001.

[18] M. Mahfouz, "The impact of the use of computer simulation method in the collection of the second level university students to test DC circuits", Unpublished Master's Thesis, University of Jordan, Jordan, 2000.

[19] M. Ronen and M. Eliahu, Simulation--a bridge between theory and reality: The case of electric circuits. Journal of Computer Assisted Learning, 16 (1), 14-26, 2000.

[20] A. Issa, "The effect of using simulation implemented through the computer as a teaching assistant method in the immediate and delayed achievement of tenth grade students in the Study of Natural Sciences", Unpublished Master Thesis, University of Jordan, Jordan, 1993.

[21] B. Yngvi and F. Hilmar, Cadia- player: a simulation-based general game player, IEEE Transactions on Computational Intelligence and AI in Games, 1(1), 1-12, 2009.

[22] Research Center, "Center for Implementing Technology in Education, Multimedia Technologies", http://www.cited.org/index.aspx?page_id=143, 2007.

[23] Z. Bashaireh and N. Afattinat, The effect of using computerized educational program in teaching chemical concepts and conducting lab experiments in the ninth grade students' achievements: chemistry and earth sciences. Damascus University Journal, 25(1), 405-442, 2009.

[24] Y. Shdeifat and T. Irshaid, The effect of using computers and the Internet in the achievements of eighth graders students in the Study of Science compared to the traditional way of teaching in Al- Mafraq city, University of Sharjah. Journal of Islamic Science and Humanitarian, 4(2), 109-142, 2007.

[25] A. M. Shehry, "The impact of the use of virtual laboratories in learning laboratory experiments skills for third grade students in secondary schools in Jeddah", Unpublished Master Thesis, Aum Al-Qura University, College of Education, Mecca, KSA, 2009.

[26] H. Y. Abu-Zaida, "Effectiveness of a multimedia program for the development of concepts and health awareness in sciences for sixth grade students", Unpublished Master Thesis, The Islamic University, College, Gaza, 2006.

[27] A. A. Darwesh, "The impact of the use of multimedia on the achievements of second-graders students in science in Riyad city", Unpublished Master Thesis, King Saud University, Riyadh, KSA, 2004.

[28] S. A. Shaker, "The effectiveness of simulation programs in achieving laboratory skills among high school students", Unpublished Doctoral Dissertation, Helwan University, Egypt, 2004.

[29] N. K. Tahan, "The impact of the use of computers in teaching physics in the achievements of female students and their motivation to learn", Unpublished Master Thesis, Baghdad University, Baghdad, Iraq, 2003.

[30] C. Y. Chang, Does-computer-assisted instruction, problem solving improves science outcomes? A pioneer study. The Journal of Educational Research, 95(3), 143-150, 2002.

[31] J. P. Akpan and T. Andre, Using a computer simulation before dissection to help students learn anatomy. Journal of Computers in Mathematics and Science Teaching, 19 (3), 297-313, 2000.

[32] K. Persichitte, Basic criteria for selecting and evaluating instructional software, In D. Willis, J. Robin \& J. Willis (Eds). Technology and Teacher Education Annual, Association for the Advancement of Computers in Education, 1995.

Dr. Ibtesam F. Al-Mashaqbeh is Associate professor, Faculty of Information Technology, Dept. of Computer Science, Al alBayt University (AABU), Mafraq-Jordan. Al-Mashaqbeh primary teaching areas are related to the use of computer applications in teaching and online teaching process. She has over 10 years teaching experience at the university levels for graduate and undergraduate levels. Her research and writing focus on pedagogical use of computer tools, and integration of specific computer tools into actual classroom instruction to support meaningful learning. 